\title{
Standardizing Pathogenicity Assays for Fusarium Wilt Pathogens of Ornamental Palms
}

\author{
Monica L. Elliott, ${ }^{\dagger}$ Department of Plant Pathology, University of Florida, Fort Lauderdale Research and Education Center, Davie 33314
}

\begin{abstract}
Standardized protocols for determining pathogenicity of Fusarium oxysporum ff. spp. canariensis and palmarum, the cause of Fusarium wilt of ornamental palms, were developed using small palm plants with a minimum of three to four seedling leaves. For both protocols, a standard amount of inoculum $\left(25 \mathrm{ml}\right.$ of $10^{6}$ spores $\left./ \mathrm{ml}\right)$ was pipetted onto and between the leaf bases of each plant, with excess material running down onto the roots and collecting in the container. After 3 days, the palm plants were transplanted into $450-\mathrm{ml}$ containers filled with pine bark/sedge peat/sand potting mix. The protocol for $F$. oxysporum f. sp. canariensis differed from the protocol of $F$. oxysporum f. sp. palmarum by requiring that the lower $20 \%$ of

roots be cut prior to inoculation and having the assay run for 6 months versus 3 months. These two assays were used to evaluate pathogenicity of multiple isolates of each pathogen. All 15 isolates of $F$. oxysporum $\mathrm{f}$. sp. palmarum were pathogenic, whereas only 7 of $13 F$. oxysporum $\mathrm{f}$. sp. canariensis isolates were pathogenic. These assays were also used to determine susceptibility of other palm species to these pathogens. Washingtonia filifera, Butia odorata, Phoenix dactylifera, and $P$. reclinata appeared susceptible to $F$. oxysporum f. sp. palmarum, at least in the seedling stage. Other inoculation techniques are described that may be useful for evaluating Fusarium wilt disease management methods.
\end{abstract}

One of the most variable aspects of plant pathology research is pathogenicity testing. For any given crop, it is a challenge to develop an inoculation protocol to deliver consistent disease pressure that will produce repeatable results. This can be especially difficult when working with diseases of mature trees, because finding enough trees of the same size for large-scale experiments can be expensive and require considerable space in a greenhouse or field nursery. To circumvent the problem, plant pathologists often develop pathogenicity assays with seedlings or small trees where results correlate with the symptoms observed in large, mature trees and where testing can be done in a manageable and controlled research facility. Ornamental tree nurseries are not usually willing to allow researchers to use their field nurseries for research for fear that the pathogen may infect their material. Moreover, using established trees in the landscape is not feasible because the researcher will have minimal control, if any, over the geographical terrain and microenvironmental conditions which can vary over large landscape areas. For palms, seedlings are preferred to larger material for safety reasons, because some palm species have spines (e.g., genera Phoenix and Washingtonia) on their petioles that can cause puncture wounds that may lead to plantthorn synovitis (Kratz et al. 2003; Stevens et al. 2000).

For almost four decades in the United States, Fusarium wilt in palms was restricted to Phoenix canariensis (Canary Island date palm), which is caused by Fusarium oxysporum f. sp. canariensis. This disease occurs worldwide (Elena 2005; Palmucci 2006; Summerell et al. 2001). It was first detected in the continental United States in California in 1976 (Feather et al. 1989), followed by Florida in 1994 (Plyler et al. 1999). This disease has continued to spread in the United States to Louisiana, Nevada, South Carolina, and Texas (Elliott et al. 2011; Singh et al. 2011; Summerell et al. 2001). In 2010, a new palm Fusarium wilt pathogen was confirmed in Florida (Elliott et al. 2010). This fungus was given the forma specialis name of "palmarum" because it had at least two common palm hosts, Washingtonia robusta and Syagrus romanzoffiana (i.e., it was not restricted to just one host species as is usually the case for Fusarium wilt pathogens). F. oxysporum f. sp. palmarum has spread

${ }^{\dagger}$ Corresponding author: M. L. Elliott; E-mail: melliott@ufl.edu

Funding: This work was supported, in part, by the United States Department of Agriculture National Institute of Food and Agriculture, Hatch project 228670 .

Accepted for publication 12 February 2018.

(c) 2018 The American Phytopathological Society throughout Florida and to other palm species, including $P$. canariensis (Elliott 2011) and $\times$ Butyagrus nabonnandi (Elliott et al. 2017).

A review of the literature revealed at least five different methods for pathogenicity testing of $F$. oxysporum $\mathrm{f}$. sp. canariensis on P. canariensis (Elena 2005; Feather 1982; Mercier and Louvet 1973; Priest and Letham 1996; Singh et al. 2011). Although all of the methods worked, some were more simple to conduct than others. However, at least three of these methods produced mixed results for pathogenicity testing of $F$. oxysporum f. sp. canariensis on $P$. dactylifera (Elena 2005; Feather et al. 1989; Mercier and Louvet 1973; Priest and Letham 1996).

For $F$. oxysporum f. sp. palmarum, three different techniques were evaluated when the pathogen was initially described in Florida (Elliott et al. 2010). One of these techniques (seedlings inoculated with spore suspension) was used again in determining pathogenicity of an isolate obtained from symptomatic $W$. robusta in Texas (Giesbrecht et al. 2013) and for confirming pathogenicity on new palm hosts (Elliott 2011; Elliott et al. 2017).

Fusarium wilt caused by $F$. oxysporum $\mathrm{ff}$. spp. canariensis and palmarum is a lethal disease of ornamental palms. Although it normally occurs as a canopy infection in the landscape, if the pathogens become incorporated into the soil, infection of the roots will occur in susceptible palm species (Elliott et al. 2010; Summerell et al. 2001), a phenomenon observed in date palm groves infested with $F$. oxysporum $\mathrm{f}$. sp. albedinis (Louvet and Toutain 1981) and oil palm plantations infested with $F$. oxysporum f. sp. elaeidis (Colhoun 1981). This root infection aspect of the disease on ornamental palms has led to the recommendations of not planting a Fusarium wilt-susceptible palm back into the same location where the previous palm died from Fusarium wilt. The question that then arises from a landscape owner is: "What palm would be acceptable to replant in this location?" The other question by landscape owners concerns methods and materials that could be used to prevent the disease or mitigate damage if a susceptible palm becomes symptomatic. Although nursery growers have the options of fumigation or sterilization, such options cannot be used in landscapes. Both of these questions could be initially investigated using a standardized plant-pathogen assay.

Because it is likely that these two formae speciales of $F$. oxysporum associated with ornamental palms will continue to spread, it would be useful to have a standardized procedure for testing pathogenicity and evaluation of potential management protocols. For example, the European and Mediterranean Plant Protection Organization (EPPO) has a standard protocol for diagnosing and determining pathogenicity of F. oxysporum f. sp. albedinis, an A2 regulatory pathogen, which causes Fusarium wilt of $P$. dactylifera (EPPO 2003). 
Therefore, the objectives of this research were to (i) develop a standard pathogenicity assay for $F$. oxysporum f. sp. palmarum, (ii) develop a standard pathogenicity assay for $F$. oxysporum $\mathrm{f}$. sp. canariensis, (iii) determine potential susceptibility of other palm species to these two Fusarium wilt pathogens, and (iv) develop a method for evaluating prevention or mitigation of Fusarium wilt using $F$. oxysporum $\mathrm{f}$. sp. palmarum as the model pathogen.

\section{Materials and Methods}

Fungal isolates and inoculum preparation. All $F$. oxysporum $\mathrm{ff}$. spp. canariensis and palmarum isolates used in this study are listed in Table 1. Single-spored isolates were stored as colonized agar plugs in sterile deionized water (SDW) in cryogenic vials sealed with Parafilm and maintained at room temperature. As needed, a plug was transferred from storage to one-fifth-strength potato dextrose agar (1/5 PDA) and incubated at $26^{\circ} \mathrm{C}$ with $12 \mathrm{~h}$ of light.

To prepare inoculum, fungal isolates were transferred from the $1 / 5$ PDA plate to full-strength PDA and incubated at $26^{\circ} \mathrm{C}$ with $12 \mathrm{~h}$ of light. After at least 2 weeks of growth, approximately $7 \mathrm{ml}$ of SDW was added to each plate and the agar surface was gently rubbed with a sterile bent glass rod to loosen asexual spores (mostly microconidia but also macroconidia) from the mycelia. This suspension was poured into a sterile bottle and the plate was rinsed with approximately $10 \mathrm{ml}$ of SDW into the bottle. The suspension was filtered through four layers of sterile cheesecloth to remove mycelia and then diluted with SDW to obtain $10^{6}$ spores $/ \mathrm{ml}$. Although the number of spores produced varied for each isolate, they all yielded a minimum of $25 \mathrm{ml}$ of $10^{6}$ spores $/ \mathrm{ml}$ per PDA plate, which became the standard amount of inoculum applied to each plant.

Standard inoculation method for pathogenicity assay. Palm seedlings were obtained in deep cell plug trays from various nurseries in Florida and Texas. Exact source depended on availability when the experiments were initiated. Only seedlings with a minimum of three to four seedling leaves were used. The inoculation method used is

Table 1. Isolates of Fusarium oxysporum f. sp. palmarum and f. sp. canariensis used in this study, with location (county and state) and palm host from which the isolate was originally obtained

\begin{tabular}{lll}
\hline Isolate & County, state & \multicolumn{1}{c}{ Palm host } \\
\hline F. oxysporum f. sp. palmarum & & \\
PLM-119C & Martin, FL & Syagrus romanzoffiana \\
PLM-140B & Broward, FL & S. romanzoffiana \\
PLM-153B & Manatee, FL & S. romanzoffiana \\
PLM-249A & Lee, FL & Washingtonia robusta \\
PLM-320B & Pinellas, FL & $\times$ Butyagrus nabonnandi \\
PLM-510A & Orange, FL & Phoenix canariensis \\
PLM-560A & St. Lucie, FL & W. robusta \\
PLM-596A & Brevard, FL & W. robusta \\
PLM-619A & Orange, FL & Bismarckia nobilis \\
PLM-676A & Broward, FL & P. canariensis \\
PLM-729A & Sarasota, FL & S. romanzoffiana \\
PLM-741A & Miami-Dade, FL & S. romanzoffiana \\
PLM-791A & Palm Beach, FL & P. canariensis \\
PLM-853A & Orange, FL & $\times$ Butyagrus nabonnandi \\
PLM-920 & Harris, TX & W. robusta \\
F. oxysporum f. sp. canariensis & & \\
PLM-183C & Miami-Dade, FL & P. canariensis \\
PLM-221B & Manatee, FL & P. canariensis \\
PLM-224A & Manatee, FL & Phoenix sylvestris \\
PLM-385B & Travis, TX & P. canariensis \\
PLM-386B & Sarasota, FL & P. canariensis \\
PLM-387B & Manatee, FL & P. reclinata \\
PLM-511A & Charleston, SC & P. canariensis \\
PLM-588A & Sarasota, FL & P. canariensis \\
PLM-605A & Duval, FL & P. canariensis \\
PLM-696A & Palm Beach, FL & P. reclinata \\
PLM-706A & Marin, CA & P. canariensis \\
PLM-724A & Duval, FL & P. canariensis \\
PLM-754A & Palm Beach, FL & P. canariensis \\
\hline & &
\end{tabular}

similar to the standard pathogenicity assay described for $F$. oxysporum f. sp. albedinis (EPPO 2003). Palm seedlings were removed from plug trays and potting mix was shaken or hand removed from the roots. Then, for each inoculum treatment, five replicate palm plants were placed in a 1- to 3-liter container. Size of the container depended on the size of the palm seedling, because a three-to-fourseedling-leaf palm will vary in size based on the palm species. The standard spore suspension $\left(25 \mathrm{ml}\right.$ of $10^{6}$ spores $\left./ \mathrm{ml}\right)$ was used per palm, with the suspension pipetted down among the leaf bases, with excess material running down onto the roots and collecting in the container. The control treatment for each experiment was always SDW at $25 \mathrm{ml} / \mathrm{palm}$. The top of the container was covered with a clear polyethylene bag, with the leaves left exposed.

After 3 days in the dark, palm plants were transplanted into 450-ml containers filled with a pine bark/sedge peat/sand $(5: 4: 1)$ potting mix amended with dolomite and micronutrients. Osmocote fertilizer was applied to the potting mix surface according to directions, which were based on container size, duration of experiment, and expected mean temperature.

Palm growth conditions and dry weights. After transplanting, plants were placed on benches in a structure with shade-cloth walls and a clear polycarbonate sheet roof, where they were irrigated daily. Because the experiments were conducted in southeastern Florida, no attempt was made to regulate temperature unless the temperature was likely to drop below $10^{\circ} \mathrm{C}$, at which time vents were closed and sidewall curtains were dropped ahead of the temperature decline to maintain ambient heat in the structure. Palm plants were examined weekly. Duration of each experiment varied as noted below. At the termination of each experiment (except for experiment 1), controltreatment palm plants and any plants surviving fungal inoculation were harvested by cutting plants at the leaf base-root interface and drying at $60^{\circ} \mathrm{C}$ for at least 5 days prior to weighing. Palm plants that died prior to termination of an experiment were give the dry weight value of 0 . Dry weights were not obtained for experiment 1 .

Experiment 1. Using the standard inoculation method, 22 palm species used in the Florida landscape were evaluated to determine their susceptibility to $F$. oxysporum $\mathrm{f}$. sp. palmarum (Table 2 ). This

Table 2. Palm species evaluated for susceptibility to Fusarium oxysporum f. sp. palmarum

\begin{tabular}{llc}
\hline Palm species & \multicolumn{1}{c}{ Common name } & Susceptibility $^{\mathbf{a}}$ \\
\hline Adonidia merrellii & Christmas or Manila palm & - \\
Allogoptera arenaria & Seashore palm & - \\
Arenga engleri & Dwarf sugar palm & - \\
Beccariophoenix alfredii & High plateau coconut palm & - \\
Butia odorata & Pindo or Jelly palm & + \\
$\times$ Butyagrus nabonnandi & Mule palm & + \\
Chamaerops humilis & European fan palm & - \\
Dypsis decaryi & Triangle palm & - \\
D. lutescens & Areca or Golden cane palm & - \\
Kentiopsis oliviformis & none & - \\
Livistona chinensis & Chinese fan palm & - \\
Phoenix canariensis & Canary Island date palm & + \\
P. dactylifera & Date palm & + \\
P. reclinata & Senegal date palm & + \\
. roebelenii & Pygmy date palm & - \\
P. sylvestris & Wild date palm & + \\
Ravenea rivularis & Majesty palm & - \\
Rhapis excelsa & Lady palm & - \\
Roystonea regia & Royal palm & - \\
Syagrus romanzoffiana & Queen palm & + \\
Thrinax radiata & Florida thatch palm & - \\
Washingtonia filifera & California or Desert fan palm & + \\
W. robusta & Mexican fan palm & + \\
Wodyetia bifurcata & Foxtail palm & - \\
\hline Synbols + indim &
\end{tabular}

${ }^{a}$ Symbols: + indicates that at least one of five replicate palm plants per fungal treatment died or severely declined compared with the water only (control) treatment and - indicates that none of the five replicate palm plants per fungal treatment died or appeared different from the control treatment. 
experiment was conducted in three repetitions. Each repetition included seven or eight different palm species, plus $W$. robusta as the susceptible control. Two $F$. oxysporum f. sp. palmarum isolates, PLM-140B and PLM-249A (treatments), were used for each repetition, plus the control (SDW only) treatment. There were five replicate palm plants per treatment-palm species. The experiment was terminated after 6 months. For each palm species, it was noted whether a fungal inoculated palm died or declined compared with their respective control treatment.

Experiment 2. W. filifera, Butia odorata, and $\times$ B. nabonnandi (a sterile, interspecific cross between $S$. romanzoffiana and $B$. odorata) were examined more closely for susceptibility to $F$. oxysporum f. sp. palmarum. S. romanzoffiana and $W$. robusta were included as the known susceptible controls. The $F$. oxysporum f. sp. palmarum isolates used were PLM-140B, PLM-249A, and PLM-320B (treatments), which represented all three haplotypes of this pathogen (Elliott et al. 2010). There were five replicate palm plants per treatment-palm species. Plants were examined weekly, and the experiment was terminated after 6 months. This experiment was repeated twice.

Experiment 3. The cross-pathogenicity of $F$. oxysporum ff. spp. canariensis and palmarum on $P$. canariensis, $P$. dactylifera, $P$. reclinata, $P$. sylvestris, $S$. romanzoffiana, and $W$. robusta was examined in this experiment. Two $F$. oxysporum $\mathrm{f}$. sp. palmarum isolates (PLM-140B and PLM-249A) and three $F$. oxysporum f. sp. canariensis isolates (PLM-224A, PLM-386B, and PLM-387B) were used as treatments. There were five replicate palm plants per treatment-palm species. Plants were examined weekly, and the experiment was terminated after 6 months. This experiment was repeated twice, except that $S$. romanzoffiana was not included in the second repetition.

Experiment 4. The results of experiment 3 with $F$. oxysporum $\mathrm{f}$. sp. canariensis were not as expected. Thus, two additional inoculation methods were compared with the standard inoculation method for the pathogenicity assay. The second inoculation method was similar to the standard method, except that the lowest $20 \%$ of the roots were cut prior to inoculation with the individual fungal suspensions or SDW. For the third inoculation method, palm plants were transplanted as described previously. Then, for each palm, a shallow (approximately $3 \mathrm{~mm}$ deep), 1.25-cm-long slit was made with a sterile scalpel on the adaxial side of the two lowest leaf petioles. Approximately $12 \mathrm{ml}$ of the spore suspension or SDW was dribbled slowly into the slits. The slits were then wrapped with Parafilm. The same three $F$. oxysporum f. sp. canariensis isolates were used as in experiment 3 but only $P$. canariensis was evaluated. There were five replicate palm plants per fungal treatment or control-inoculation method. Plants were examined weekly, and the experiment was terminated after 6 months.

Experiment 5. Because the cutting of the lowest $20 \%$ of the roots in experiment 4 appeared to provide consistent pathogenicity results for $P$. canariensis across all three $F$. oxysporum f. sp. canariensis isolates, this method was used for a duplication of experiment 3 . In other words, all palm species had $20 \%$ of the lowest roots removed prior to inoculation with individual fungal spore suspensions of $F$. oxysporum ff. spp. canariensis and palmarum or SDW. Palm plants were examined weekly, and the experiment was terminated after 6 months. This experiment was repeated twice, except that $P$. reclinata was not included in the second repetition.

Experiment 6. To determine the consistency of the two inoculation methods-with or without cutting the lower roots-for pathogenicity assays, an experiment was established as follows. The method that appeared to be successful for $F$. oxysporum f. sp. palmarum did not include the cutting of roots. This method, as described initially, was used on $W$. robusta, with 15 different $F$. oxysporum f. sp. palmarum isolates plus a SDW control. The method that appeared to be successful for $F$. oxysporum f. sp. canariensis did include cutting the lower $20 \%$ of the roots. This method, as described in experiments 4 and 5, was used on $P$. canariensis, with 13 different $F$. oxysporum f. sp. canariensis isolates plus a SDW control. There were five replicate palm plants per fungal- and control treatments-palm species. Plants were examined weekly. The experiment with $W$. robusta was terminated after 3 months; the experiment with $P$. canariensis was terminated after 6 months.
Experiment 7. Although the level of disease obtained with F. oxysporum $\mathrm{f}$. sp. palmarum using the standard inoculation method was useful for examining pathogenicity of $F$. oxysporum f. sp. palmarum isolates, a less severe method is needed for evaluating chemical and biological management methods. Therefore, another inoculation method was examined. Seedlings of $W$. robusta were transplanted as described previously and then allowed to grow undisturbed in a covered shadehouse until the palm plants had established with two new, fully emerged leaves. At this point, three different root disturbance techniques and four different levels of inoculum, using only isolate PLM-249A, were used for treatments. The three root disturbance techniques were (i) no disturbance, (ii) the top potting-mix layer (approximately $625 \mathrm{~mm}$ deep) was scraped to the edges of the pot with a sterile metal tool to disturb the fine roots growing in this top layer, and (iii) the top layer was scraped away as above plus roots were cut vertically in the pot at three places using pruners. The level of inoculum used was either $0,5,15$, or $25 \mathrm{ml}$ of the $10^{6}$ spores $/ \mathrm{ml}$ suspension and was applied among the leaf bases, with excess percolating into the potting mix. For root disturbance techniques (ii) and (iii), the inoculum was applied after the roots were disturbed and then the top layer was scraped back over the roots. There were five replicate palm plants per root disturbance technique-inoculum level. Plants were examined weekly, and the experiment was terminated after 6 months. This experiment was repeated three times.

Statistical analysis. For experiments 2 through 6, the General Linear Models (GLM) procedure in SAS 9.4 (SAS Institute, Inc., Cary, NC) was used. Means were compared using Dunnett's test (Dunnett 1955), with all means within a species compared against the control treatment for that species. Mean, standard error, and Dunnett's test were calculated using SAS 9.4. For experiment 7, data from all three repetitions were combined and a two-way analysis of variance (ANOVA) was applied to the data (PROC GLM in SAS 9.4).

\section{Results}

A preliminary experiment using the standard inoculation method, with $W$. robusta and $S$. romanzoffiana as the hosts and $F$. oxysporum f. sp. palmarum isolates PLM-140B and PLM-249B as the pathogens, was conducted prior to initiating any of the other experiments. All five replicate plants of each palm species inoculated with either pathogen were killed within 3 months, whereas all control plants (SDW only) were healthy (data not shown).

Experiment 1. Based on the preliminary experiment results, the standard inoculation method was used to evaluate $F$. oxysporum f. sp. palmarum susceptibility of 22 palm species used in the Florida landscape. Other than $S$. romanzoffiana and $W$. robusta, of which all five replicate plants of each species died after inoculation with PLM140B and PLM-249A, the following were the only palm species where at least one of five replicate plants died or severely declined due to inoculation, compared with their respective controls: $B$. odorata, $\times$ B. nabannandi, $P$. canariensis, $P$. dactylifera, $P$. reclinata, $P$. sylvestris, and $W$. filifera (Table 2). All the other palm species remained healthy after inoculation with both isolates of $F$. oxysporum $\mathrm{f}$. sp. palmarum. Of note is the fact that $P$. roebelenii was not affected by this pathogen, even though the other four Phoenix spp. tested were affected. To be certain, $P$. roebelenii was evaluated a second time and the results were the same (data not shown).

Experiment 2. Previous studies combined with the results of experiment 1 prompted a further examination of $F$. oxysporum f. sp. palmarum haplotype susceptibility of $W$. filifera, $B$. odorata, and $\times$ B. nabonnandi using the standard inoculation method for the pathogenicity assay (Elliott et al. 2017; Giesbrecht et al. 2013). In both repetitions of the experiment, all three palm species, as well as $W$. robusta and $S$. romanzoffiana, had dry leaf weights that were significantly lower from the controls (Table 3 ). For all palm species, no matter which fungal isolate was used, either all five replicate palm plants died or the mean dry leaf weight was reduced by $75 \%$ or greater (Table 3 ).

Experiment 3. In this cross-pathogenicity experiment, all W. robusta and $S$. romanzoffiana plants inoculated with $F$. oxysporum f. sp. palmarum died but none died when inoculated with $F$. oxysporum f. sp. canariensis (Table 4). In the first repetition using $F$. oxysporum 
f. sp. palmarum, all inoculated $P$. dactylifera plants died, and $P$. reclinata dry leaf weight was significantly reduced by isolate PLM-140B. In the second repetition, $P$. reclinata dry leaf weight was significantly reduced by both isolates but only isolate PLM-249A significantly reduced the dry leaf weight of $P$. dactylifera.

In contrast, only the $F$. oxysporum f. sp. canariensis isolate PLM387B, which was originally isolated from $P$. reclinata, significantly affected dry leaf weights of $P$. canariensis (both repetitions), P. reclinata (both repetitions), and $P$. sylvestris (only one repetition) (Table 4). The other two isolates had no significant effects on any of the other plant species tested.

Experiment 4. It had been expected that all of the $F$. oxysporum $\mathrm{ff}$. spp. palmarum and canariensis isolates would be pathogenic on
$P$. canariensis. However, in experiment 3 , this palm species was only affected by one $F$. oxysporum f. sp. canariensis isolate. These conflicting results suggested that the standard inoculation method for the pathogenicity assay for $F$. oxysporum f. sp. palmarum may not be applicable for $F$. oxysporum f. sp. canariensis. Therefore, an experiment was conducted to examine additional inoculation methods for $F$. oxysporum f. sp. canariensis on $P$. canariensis. The two new inoculation methods-removal of $20 \%$ of the lower roots prior to inoculation and inoculation via a petiole incision-were compared against the standard inoculation method for the $F$. oxysporum $\mathrm{f}$. $\mathrm{sp}$. palmarum pathogenicity assay. Cutting the lower $20 \%$ of the roots prior to inoculation provided consistent and significant decrease in dry leaf weight compared with the control treatment plants and the

Table 3. Leaf dry weight of palm species inoculated with three haplotypes of Fusarium oxysporum f. sp. palmarum compared with control (water only) plants of each species in two repetitions of the experiment

\begin{tabular}{|c|c|c|c|c|c|}
\hline \multirow[b]{2}{*}{ Treatment $^{b}$} & \multicolumn{5}{|c|}{ Leaf dry weight $(\mathrm{g})^{\mathrm{a}}$} \\
\hline & $\mathbf{W r}$ & Wf & $\mathrm{Sr}$ & Bo & Bn \\
\hline \multicolumn{6}{|l|}{ Trial 1} \\
\hline Control & $37.7 \pm 2.0$ & $47.9 \pm 4.0$ & $22.3 \pm 2.9$ & $31.5 \pm 2.5$ & $20.5 \pm 1.9$ \\
\hline PLM-140B & $0 *$ & $0 *$ & $0 *$ & $6.7^{*} \pm 4.1$ & $0^{*}$ \\
\hline PLM-246A & $0^{*}$ & $0^{*}$ & $3.3^{*} \pm 3.3$ & $2.4^{*} \pm 2.4$ & $0^{*}$ \\
\hline PLM-320B & $8.8^{*} \pm 8.8$ & $0^{*}$ & $1.1 * \pm 1.1$ & $6.9 * \pm 0.7$ & $0^{*}$ \\
\hline MSD & 16.6 & 7.2 & 8.4 & 9.9 & 3.5 \\
\hline \multicolumn{6}{|l|}{ Trial 2} \\
\hline Control & $54.6 \pm 1.8$ & $23.0 \pm 3.1$ & $17.8 \pm 0.6$ & $29.3 \pm 3.1$ & $18.1 \pm 1.7$ \\
\hline PLM-140B & $0 *$ & $0^{*}$ & $5.1 * \pm 3.2$ & $7.7 * \pm 5.0$ & $2.4^{*} \pm 2.4$ \\
\hline PLM-246A & $0^{*}$ & $1.7^{*} \pm 1.7$ & $0^{*}$ & $7.9 * \pm 3.7$ & $0^{*}$ \\
\hline PLM-320B & $0^{*}$ & $0^{*}$ & $4.3^{*} \pm 2.8$ & $0^{*}$ & $2.6^{*} \pm 2.6$ \\
\hline MSD & 3.3 & 6.6 & 7.8 & 12.7 & 7.2 \\
\hline
\end{tabular}

${ }^{a}$ Mean dry weight of five replicate plants \pm standard error. Note: If the standard error is the same as the dry weight mean, this indicates that only one of five replicate plants was still living at the time the experiment was terminated. Plants that had died by the time the experiment was terminated were given a dry weight value of " 0 ". Within each column, a fungal treatment mean value followed by an asterisk $(*)$ indicates that the mean is significantly different $(P=0.05)$ from the control (water only) mean using Dunnett's $t$ test. Palm species abbreviations: $\mathrm{Wr}=$ Washingtonia robusta, $\mathrm{Wf}=$ W. filifera, $\mathrm{Sr}=S y a g r u s$ romanzoffiana, $\mathrm{Bo}=$ Butia odorata, and $\mathrm{Bn}=\times$ Butyagrus nabonnandi .

${ }^{\mathrm{b}} \mathrm{MSD}=$ minimum significant difference.

Table 4. Leaf dry weight of six palm species inoculated with two isolates of Fusarium oxysporum f. sp. palmarum and three isolates of $F$. oxysporum f. sp. canariensis compared with control (water only) plants of each species in two repetitions of the experiment ${ }^{\mathrm{a}}$

\begin{tabular}{|c|c|c|c|c|c|c|}
\hline \multirow[b]{2}{*}{ Treatment $^{\mathrm{c}}$} & \multicolumn{6}{|c|}{ Leaf dry weight $(g)^{b}$} \\
\hline & $\mathbf{W r}$ & $\mathrm{Sr}$ & Pc & Pd & Pr & Ps \\
\hline \multicolumn{7}{|l|}{ Trial 1} \\
\hline Control & $26.1 \pm 0.8$ & $11.2 \pm 2.1$ & $6.9 \pm 0.4$ & $11.2 \pm 2.1$ & $7.7 \pm 0.8$ & $12.6 \pm 1.6$ \\
\hline \multicolumn{7}{|c|}{ F. oxysporum f. sp. palmarum } \\
\hline PLM-140B & $0 *$ & $0 *$ & $3.4 \pm 1.5$ & $0 *$ & $3.8 \pm 1.0^{*}$ & $7.7 \pm 0.7$ \\
\hline PLM-249A & $0^{*}$ & $0^{*}$ & $4.0 \pm 1.3$ & $0^{*}$ & $4.5 \pm 1.5$ & $8.2 \pm 2.2$ \\
\hline \multicolumn{7}{|c|}{ F. oxysporum f. sp. canariensis } \\
\hline PLM-224A & $26.1 \pm 2.1$ & $11.9 \pm 2.3$ & $5.2 \pm 1.4$ & $11.9 \pm 2.3$ & $5.7 \pm 1.1$ & $9.5 \pm 1.6$ \\
\hline PLM-386B & $29.3 \pm 2.1$ & $16.2 \pm 1.6$ & $6.1 \pm 0.6$ & $16.2 \pm 1.6$ & $7.0 \pm 0.4$ & $10.9 \pm 1.0$ \\
\hline PLM-387B & $23.4 \pm 1.5$ & $13.4 \pm 3.2$ & $2.6 \pm 0.8^{*}$ & $13.4 \pm 3.2$ & $1.8 \pm 0.8^{*}$ & $5.8 \pm 2.2 *$ \\
\hline MSD & 5.34 & 7.36 & 4.07 & 7.36 & 3.85 & 6.30 \\
\hline \multicolumn{7}{|l|}{ Trial 2} \\
\hline Control & $27.6 \pm 1.8$ & $\ldots$ & $10.5 \pm 1.5$ & $14.0 \pm 0.5$ & $16.7 \pm 2.7$ & $9.1 \pm 1.0$ \\
\hline \multicolumn{7}{|c|}{ F. oxysporum f. sp. palmarum } \\
\hline PLM-140B & $0^{*}$ & $\ldots$ & $5.7 \pm 1.1$ & $8.0 \pm 2.4$ & $4.2 \pm 3.4^{*}$ & $8.2 \pm 0.6$ \\
\hline PLM-249A & $0 *$ & $\ldots$ & $7.6 \pm 1.9$ & $0.6 \pm 0.6^{*}$ & $7.8 \pm 2.0^{*}$ & $6.4 \pm 1.1$ \\
\hline \multicolumn{7}{|c|}{ F. oxysporum f. sp. canariensis } \\
\hline PLM-224A & $29.7 \pm 0.7$ & $\ldots$ & $12.3 \pm 0.9$ & $10.4 \pm 1.9$ & $18.8 \pm 1.9$ & $10.2 \pm 2.8$ \\
\hline PLM-386B & $26.7 \pm 2.7$ & $\ldots$ & $10.1 \pm 1.7$ & $12.5 \pm 2.3$ & $17.8 \pm 2.0$ & $8.8 \pm 1.2$ \\
\hline PLM-387B & $22.5 \pm 2.9$ & $\ldots$ & $3.8 \pm 1.7^{*}$ & $8.5 \pm 1.9$ & $2.0 \pm 0.6^{*}$ & $7.4 \pm 0.8$ \\
\hline MSD & 7.14 & $\ldots$ & 5.58 & 6.75 & 8.60 & 5.45 \\
\hline
\end{tabular}

a Palm roots were not cut prior to inoculation in this experiment.

b Mean dry weight of five replicate plants \pm standard error. Note: If the standard error is the same as the dry weight mean this indicates that only one of five replicate plants was still living at the time the experiment was terminated. Plants that had died by the time the experiment was terminated were given a value of " 0 ". Within each column, a fungal treatment mean value followed by an asterisk $(*)$ indicates the treatment mean is significantly different $(P=0.05)$ from the control (water only) mean using Dunnett's $t$ test. Palm species abbreviations: $\mathrm{Wr}=$ Washingtonia robusta, $\mathrm{Sr}=$ Syagrus romanzoffiana, $\mathrm{Pc}=$ Phoenix canariensis, $\mathrm{Pd}=P$. dactylifera, $\mathrm{Pr}=P$. reclinata, and $\mathrm{Ps}=P$. sylvestris .

${ }^{\mathrm{c}} \mathrm{MSD}=$ minimum significant difference. 
other two methods (Table 5). The petiole incision technique appeared to be useful for only one of the three $F$. oxysporum f. sp. canariensis isolates. Thus, cutting the roots prior to pathogen inoculation became the new "standard" inoculation method for the $F$. oxysporum f. sp. canariensis pathogenicity assays for the remaining experiments with this pathogen.

Experiment 5. Based on the results of experiment 4, this new standard inoculation method for $F$. oxysporum $\mathrm{f}$. sp. canariensis was used for a duplication of experiment 3 . The same isolates and the same palm species as used in experiment 3 were used again but, this time, $20 \%$ of the lowest roots were cut from all the palm species.

Except for $P$. sylvestris, inoculation with both $F$. oxysporum $\mathrm{f}$. sp. palmarum isolates resulted in consistently reduced dry leaf weights compared with their respective control treatments (Table 6). P. sylvestris was affected by PLM-249A but only in one repetition of this experiment. The increase in consistent results was observed only for P. canariensis.

Table 5. Leaf dry weight (grams) of Phoenix canariensis inoculated with three isolates of Fusarium oxysporum f. sp. canariensis using three different methods of inoculation ${ }^{\mathrm{a}}$

\begin{tabular}{lclc}
\hline Treatment $^{\mathbf{b}}$ & Roots not cut & Roots cut & Petiole incision \\
\hline Control & $6.2 \pm 0.5$ & $7.6 \pm 0.5$ & $12.5 \pm 1.2$ \\
PLM-224B & $4.7 \pm 1.1$ & $1.5 \pm 0.9^{*}$ & $9.6 \pm 1.3$ \\
PLM-386B & $4.9 \pm 1.0$ & $1.1 \pm 1.1^{*}$ & $12.2 \pm 0.4$ \\
PLM-387B & $3.4 \pm 1.0$ & $1.1 \pm 0.7^{*}$ & $7.1 \pm 0.4^{*}$ \\
MSD & 3.40 & 3.13 & 4.01 \\
\hline
\end{tabular}

a The three methods of inoculation included roots not cut prior to inoculation, roots cut prior to inoculation, and roots not cut but petiole incision made prior to inoculation. See text for more details on inoculation methods. Within each column, a fungal treatment mean value followed by an asterisk (*) indicates the treatment mean is significantly different $(P=0.05)$ from the control (water only) mean using Dunnett's $t$ test. Mean is dry weight of five replicate plants \pm standard error.

${ }^{b} \mathrm{MSD}=$ minimum significant difference
F. oxysporum f. sp. canariensis isolate PLM-386B did not affect any of the plant species tested (Table 6). PLM-224A did significantly affect $P$. canariensis and $P$. reclinata. PLM-387B significantly decreased dry leaf weight of $P$. canariensis, $P$. reclinata, and $P$. sylvestris (Table 6).

Experiment 6. The lack of consistent pathogenicity results with F. oxysporum f. sp. canariensis but not f. sp. palmarum led to experiment 6 . We wanted to know if the problem being observed was due to the inoculation technique or to a variation in the isolates of each palm pathogen. Only one primary host of each formae speciales was used in this study, which compared pathogenicity of 13 or 15 isolates of $F$. oxysporum ff. spp. canariensis and palmarum, respectively.

Using the standard $F$. oxysporum $\mathrm{f}$. sp. palmarum pathogenicity assay (no roots cut), all $15 F$. oxysporum f. sp. palmarum isolates evaluated on $W$. robusta resulted in significantly reduced dry leaf weights compared with the control treatment (Table 7). Eight isolates killed all five replicate plants and the other seven isolates reduced dry leaf weight by greater than $50 \%$ and included at least two dead replicate plants.

In contrast, using the standard $F$. oxysporum $\mathrm{f}$. sp. canariensis pathogenicity assay (20\% of roots cut) and $P$. canariensis, only 2 of the $13 F$. oxysporum f. sp. canariensis isolates killed all five replicate plants (Table 7). Another five isolates significantly reduced dry leaf weight compared with the control treatment, two isolates reduced dry leaf weight but not significantly, and four had dry leaf weights nearly the same or greater than the control treatment (Table 7). These results indicated a distinct virulence difference between formae speciales.

Experiment 7. Although death of palm plants is definitive for pathogenicity, this level of disease makes it difficult to evaluate possible chemical or biological control methods. For those types of evaluations, death of $50 \%$ or fewer plants would be preferred or, perhaps, no death at all but simply reduced growth. This was the logic behind the experiment using $W$. robusta plants that were preplanted in containers and then adding $F$. oxysporum $\mathrm{f}$. sp. palmarum inoculum, either with or without root disturbances. The two-way ANOVA

Table 6. Leaf dry weight of six palm species inoculated with two isolates of Fusarium oxysporum f. sp. palmarum and three isolates of $F$. oxysporum f. sp. canariensis compared with control (water only) plants of each species in two repetitions of the experiment ${ }^{\mathrm{a}}$

\begin{tabular}{|c|c|c|c|c|c|c|}
\hline \multirow[b]{2}{*}{ Treatment $^{\mathrm{c}}$} & \multicolumn{6}{|c|}{ Leaf dry weight (g) } \\
\hline & Wr & $\mathrm{Sr}$ & Pc & Pd & Pr & Ps \\
\hline \multicolumn{7}{|l|}{ Trial 1} \\
\hline Control & $30.8 \pm 1.1^{\mathrm{c}}$ & $12.3 \pm 1.4$ & $21.0 \pm 2.3$ & $7.1 \pm 1.1$ & $7.1 \pm 0.9$ & $13.5 \pm 1.7$ \\
\hline \multicolumn{7}{|c|}{ F. oxysporum f. sp. palmarum } \\
\hline PLM-140B & $0 *$ & $5.7 \pm 3.1^{*}$ & $1.2 \pm 1.2 *$ & $0.4 \pm 0.4^{*}$ & $1.6 \pm 0.6^{*}$ & $11.4 \pm 2.4$ \\
\hline PLM-249A & $0 *$ & $4.4 \pm 2.7^{*}$ & $0^{*}$ & $0.8 \pm 0.7 *$ & $1.0 \pm 0.6^{*}$ & $9.5 \pm 1.4$ \\
\hline \multicolumn{7}{|c|}{ F. oxysporum f. sp. canariensis } \\
\hline PLM-224A & $31.2 \pm 1.8$ & $6.7 \pm 0.4$ & $0^{*}$ & $8.4 \pm 1.2$ & $1.8 \pm 0.5^{*}$ & $8.9 \pm 2.9$ \\
\hline PLM-386B & $32.2 \pm 0.7$ & $7.9 \pm 0.4$ & $14.2 \pm 1.1$ & $10.5 \pm 1.1$ & $6.1 \pm 0.7$ & $15.1 \pm 1.8$ \\
\hline PLM-387B & $22.5 \pm 5.8$ & $7.6 \pm 2.4$ & $0.5 \pm 0.5^{*}$ & $9.7 \pm 1.4$ & $1.2 \pm 0.6^{*}$ & $2.4 \pm 1.8^{*}$ \\
\hline MSD & 9.76 & 7.79 & 4.5 & 3.90 & 2.5 & 7.82 \\
\hline \multicolumn{7}{|l|}{ Trial 2} \\
\hline Control & $22.1 \pm 1.4$ & $15.1 \pm 2.2$ & $7.3 \pm 0.6$ & $11.7 \pm 1.6$ & $\ldots$ & $10.9 \pm 2.0$ \\
\hline \multicolumn{7}{|c|}{ F. oxysporum f. sp. palmarum } \\
\hline PLM-140B & $0 *$ & $0^{*}$ & $0.8 \pm 0.5^{*}$ & $4.5 \pm 1.2 *$ & $\ldots$ & $6.4 \pm 0.9$ \\
\hline PLM-249A & $0 *$ & $0^{*}$ & $0^{*}$ & $2.4 \pm 0.8^{*}$ & $\ldots$ & $3.5 \pm 1.5^{*}$ \\
\hline \multicolumn{7}{|c|}{ F. oxysporum f. sp. canariensis } \\
\hline PLM-224A & $19.8 \pm 0.5$ & $11.9 \pm 2.3$ & $0.7 \pm 0.5^{*}$ & $5.9 \pm 1.6$ & $\ldots$ & $6.0 \pm 0.7$ \\
\hline PLM-386B & $21.8 \pm 0.6$ & $16.2 \pm 1.6$ & $5.1 \pm 1.1$ & $6.0 \pm 2.3$ & $\ldots$ & $6.4 \pm 0.8$ \\
\hline PLM-387B & $22.1 \pm 1.6$ & $13.4 \pm 3.2$ & $0.9 \pm 0.7 *$ & $7.6 \pm 1.9$ & $\ldots$ & $5.2 \pm 1.6^{*}$ \\
\hline MSD & 3.58 & 7.43 & 2.51 & 6.36 & $\cdots$ & 5.14 \\
\hline
\end{tabular}

a Palm roots (lower 20\%) were cut prior to inoculation in this experiment.

b Mean dry weight of five replicate plants \pm standard error. Note: If the standard error is the same as the dry weight mean this indicates that only one of five replicate plants was still living at the time the experiment was terminated. Plants that had died by the time the experiment was terminated were given the dry weight value of " 0 ". Within each column, a fungal treatment mean value followed by an asterisk (*) indicates the treatment mean is significantly different $(P=0.05)$ from the control (water only) mean using Dunnett's $t$ test. Palm species abbreviations: $\mathrm{Wr}=$ Washingtonia robusta, $\mathrm{Sr}=$ Syagrus. romanzoffiana, $\mathrm{Pc}=$ Phoenix canariensis, $\mathrm{Pd}=P$. dactylifera, $\mathrm{Pr}=P$. reclinata, and $\mathrm{Ps}=P$. sylvestris.

${ }^{c} \mathrm{MSD}=$ minimum significant difference. 
indicated that there was no significant interaction between root disturbance technique and inoculum level $(F=2.27 ; P=0.1059)$. However, root disturbance technique was significant $(F=9.24 ; P=$ $0.0002)$ and inoculum level was highly significant $(F=86.02 ; P<$ $0.0001)$. Addition of the highest level of inoculum $(25 \mathrm{ml})$ without any root disturbance did significantly reduce dry leaf weight compared with the noninoculated plants (Fig. 1). With a minimal amount of root disturbance, the amount of inoculum could be reduced to $5 \mathrm{ml}$ and essentially achieve the same level of reduced dry weight as the 25-ml inoculum without root disturbance. Cutting the roots prior to adding inoculum, no matter what level of inoculum was used, was too severe a technique for the intended purpose.

\section{Discussion}

The EPPO has developed standardized protocols for regulated pathogens, including $F$. oxysporum $\mathrm{f}$. sp. albedinis which causes Fusarium wilt of $P$. dactylifera (EPPO 2003). The EPPO's protocol for determining pathogenicity starts by growing the fungus on PDA at $25^{\circ} \mathrm{C}$ for 7 days, preparing an inoculum suspension at $10^{6}$ spores $/ \mathrm{ml}$ of suspension, and then pipetting the suspension onto the roots of twoleaf-stage seedlings of $P$. dactylifera (the amount per palm is not

Table 7. Leaf dry weight and number of dead plants of Washingtonia robusta due to inoculation with isolates of Fusarium oxysporum f. sp. palmarum and of Phoenix canariensis due to inoculation with isolates of $F$. oxysporum $\mathrm{f}$. sp. canariensis $^{\mathrm{a}}$

\begin{tabular}{|c|c|c|}
\hline Palm species, isolate ${ }^{\mathrm{b}}$ & Dry weight $(g)^{\mathbf{c}}$ & Dead plants $(n)$ \\
\hline \multicolumn{3}{|c|}{$\begin{array}{l}\text { W. robusta } \times F \text {. oxysporum } \mathrm{f} \text {. sp. } \\
\text { palmarum }\end{array}$} \\
\hline Control & $6.3 \pm 0.8$ & 0 \\
\hline PLM-119C & $0^{*}$ & 5 \\
\hline PLM-140B & $1.7 \pm 1.7 *$ & 4 \\
\hline PLM-153B & $0^{*}$ & 5 \\
\hline PLM-249A & $1.4 \pm 1.4^{*}$ & 4 \\
\hline PLM-320B & $0^{*}$ & 5 \\
\hline PLM-510A & $0 *$ & 5 \\
\hline PLM-560A & $0^{*}$ & 5 \\
\hline PLM-596A & $1.7 \pm 1.7 *$ & 4 \\
\hline PLM-619A & $1.0 \pm 1.0^{*}$ & 4 \\
\hline PLM-676A & $0.6 \pm 0.6^{*}$ & 4 \\
\hline PLM-729A & $0^{*}$ & 5 \\
\hline PLM-741A & $1.5 \pm 1.0^{*}$ & 3 \\
\hline PLM-791A & $0 *$ & 5 \\
\hline PLM-853A & $0^{*}$ & 5 \\
\hline PLM-920 & $2.3 \pm 1.2 *$ & 2 \\
\hline \multicolumn{3}{|c|}{$\begin{array}{l}\text { P. canariensis } \times F \text {. oxysporum } \mathrm{f} \text {. sp. } \\
\quad \text { canariensis }\end{array}$} \\
\hline Control & $7.5 \pm 0.7$ & 0 \\
\hline PLM-183C & $0.9 \pm 0.6^{*}$ & 3 \\
\hline PLM-221B & $8.3 \pm 1.0$ & 0 \\
\hline PLM-224A & $4.5 \pm 2.0$ & 2 \\
\hline PLM-385B & $2.1 \pm 1.0^{*}$ & 2 \\
\hline PLM-386B & $9.0 \pm 0.3$ & 0 \\
\hline PLM-387B & $0^{*}$ & 5 \\
\hline PLM-511A & $4.0 \pm 1.3$ & 1 \\
\hline PLM-588A & $2.4 \pm 1.4 *$ & 3 \\
\hline PLM-605A & $7.2 \pm 1.4$ & 0 \\
\hline PLM-696A & $0.8 \pm 0.6^{*}$ & 3 \\
\hline PLM-706A & $2.0 \pm 1.3 *$ & 3 \\
\hline PLM-724A & $7.0 \pm 0.5$ & 0 \\
\hline PLM-754A & $0^{*}$ & 5 \\
\hline \multicolumn{3}{|c|}{$\begin{array}{l}\text { a Mean dry weight of five replicate plants } \pm \text { standard error. Plants that had died } \\
\text { by the time the experiment was terminated were give the dry weight value of } \\
\text { " } 0 \text { ". Minimum significant difference for } W \text {. robusta }=3.61 \text {. Minimum sig- } \\
\text { nificant difference for } P \text {. canariensis }=4.18 \text {. } \\
\text { b Control = water only. } \\
\text { " Using Dunnett's } t \text { test, a fungal treatment mean value followed by an asterisk } \\
\text { (*) indicates the mean is significantly different }(P=0.05) \text { from the control } \\
\text { (water only) mean. }\end{array}$} \\
\hline
\end{tabular}

indicated). Unfortunately, no such protocol exist for $F$. oxysporum $\mathrm{f}$. sp. canariensis, even though this fungus has been documented as a pathogen for almost as long as F. oxysporum $\mathrm{f}$. sp. albedinis (Mercier and Louvet 1973). There also is no standard protocol for testing pathogenicity of $F$. oxysporum $\mathrm{f}$. sp. palmarum, the newest Fusarium wilt pathogen of palm.

It can be argued that there is no need for pathogenicity studies for identification purposes, because $F$. oxysporum isolates can be identified via sequencing of a portion of the translation elongation factor $1-\alpha$ (Geiser et al. 2004). However, simply isolating a fungus and identifying it as a pathogen does not mean the fungus is pathogenic, nor does it inform us of the pathogen's virulence level. Therefore, pathogenicity studies are still quite useful for these purposes and also for evaluating potential management methods.

Based on the experiments conducted here, the recommended protocol to determine pathogenicity of $F$. oxysporum $\mathrm{f}$. sp. palmarum would include the following steps: (i) palm plants should have a minimum of three to four seedling leaves; (ii) palm seedlings are removed from the potting mix or soil they were growing in, and this material is shaken from the roots; (iii) for each pathogen isolate or control (water only) treatment, replicate plants are placed in containers large enough to include all roots and the lower 5 to $10 \mathrm{~cm}$ of leaf bases; (iv) $25 \mathrm{ml}$ of a $10^{6}$ spores $/ \mathrm{ml}$ suspension is then pipetted onto and between the leaf bases of each palm, with excess flowing down onto the roots; (v) the container is covered with plastic, such that the leaf bases and roots are covered but not the leaf blades; (vi) plants remain in the dark or out of direct sunlight at ambient temperature for 3 days; and (vii) plants are then removed from the containers with inoculum and transplanted into containers with appropriate potting mix, fertilized, and irrigated as needed to maintain adequate soil moisture. Palm plants are monitored on a weekly basis for symptom development for a minimum of 3 months. Determining dry leaf weight may be useful for treatment comparison.

For F. oxysporum f. sp. canariensis, this same protocol would be used, except that, during the second step, approximately $20 \%$ of the root system would be cut off with a sharp pruning tool. Also, the experiment should be extended to run for a minimum of 6 months, because pathogenicity of isolates appears to be inconsistent and the pathogen may not be as virulent as $F$. oxysporum $\mathrm{f}$. sp. palmarum. Both techniques, including the size of the palm plants used, are similar to those described before for $F$. oxysporum $\mathrm{f}$. sp. albedinis (EPPO 2003; Louvet and Toutain 1981) and F. oxysporum f. sp. elaeidis (Colhoun 1981).

In my experience, most $F$. oxysporum f. sp. canariensis isolates are not as virulent as $F$. oxysporum $\mathrm{f}$. sp. palmarum isolates. Mature

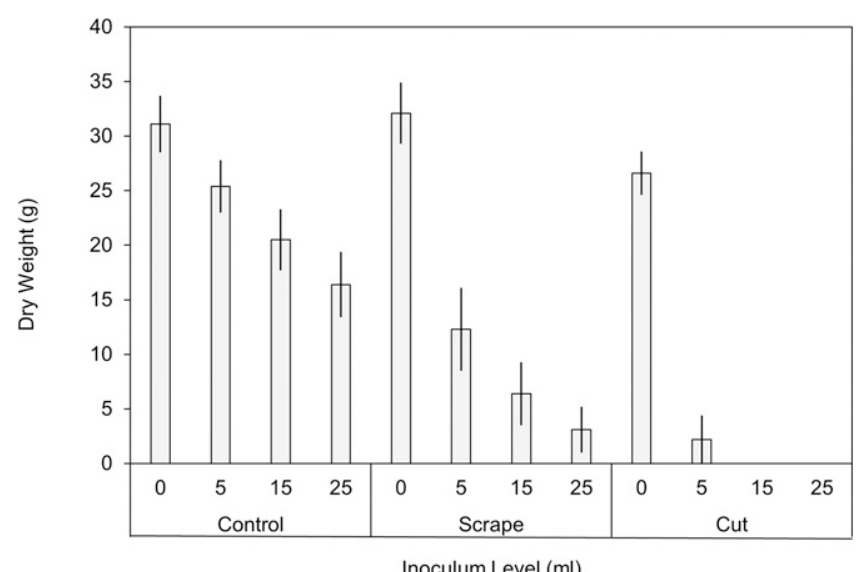

Fig. 1. Leaf dry weight (grams) of Washingtonia robusta obtained 6 months after inoculation with Fusarium oxysporum f. sp. palmarum. Three techniques were used for inoculation with either $0,5,15$, or $25 \mathrm{ml}$ of $10^{6}$ spores $/ \mathrm{ml}$ of suspension. The techniques were no root disturbance (control), top $625 \mathrm{~mm}$ of potting mix with roots disturbed (scrape), or top $625 \mathrm{~mm}$ of potting mix with roots disturbed plus three vertical cuts made to the roots internal to the container (cut). Values are mean \pm standard error of 15 replicate plants for each technique-inoculum amount treatment. 
palm plants infected with $F$. oxysporum f. sp. palmarum, even $P$. canariensis, usually die within 2 to 3 months after initial symptoms are observed (Elliott et al. 2010), whereas mature plants of $P$. canariensis infected with $F$. oxysporum $\mathrm{f}$. sp. canariensis die at a much slower space and can take as long as 2 years (Summerell et al. 2001). This difference in virulence between the two formae speciales was demonstrated with the results of experiment 6 (Table 7). In the evaluation of 15 different $F$. oxysporum $\mathrm{f}$. sp. palmarum isolates, either all the palm plants were killed or overall dry leaf weight was reduced by greater than $75 \%$ within 3 months. I have yet to encounter an isolate of $F$. oxysporum f. sp. palmarum that loses pathogenicity over time, even though some of my original isolates (e.g., PLM140B) have been stored for over 10 years.

This is in contrast with $F$. oxysporum $\mathrm{f}$. sp. canariensis. Until I began using the protocol where the roots were cut prior to inoculation, consistent results were elusive. Although all $15 \mathrm{~F}$. oxysporum f. sp. palmarum isolates evaluated were pathogenic, not all of the 13 $F$. oxysporum f. sp. canariensis isolates were, even though these isolates were obtained from Fusarium wilt-symptomatic palm plants and identified as $F$. oxysporum $\mathrm{f}$. sp. canariensis using sequencing data. Of the $13 F$. oxysporum $\mathrm{f}$. sp. canariensis isolates evaluated in experiment 6 , only 2 killed all five replicate plants and an additional 5 had significantly reduced dry leaf weights (Table 7). In other words, just over half the isolates would be considered pathogenic. Also, palm decline occurred at a much slower pace, requiring that the experiment be run for 6 months, rather than the shorter time ( 3 months) required for the $F$. oxysporum f. sp. palmarum pathogenicity assay. The repeated use of PLM-386B in the experiments also illustrates the issue of loss of pathogenicity over time, because it was pathogenic in one experiment (Table 4) but not in later experiments (Tables 5 and 7). The same is true for PLM-511A, which had been pathogenic in a previous study (Elliott et al. 2011) but was not in the current study (Table 7).

Based on the results presented regarding potentially susceptible hosts for $F$. oxysporum f. sp. palmarum, palm plants that have been observed to die in the landscape also die, or their dry leaf weight is significantly reduced, in the pathogenicity assay. These would include $W$. robusta, $S$. romanzoffiana, $\times B$. nabonnandi, and $P$. canariensis (Elliott 2011; Elliott et al. 2010, 2017).

With the intergeneric cross of S. romanzoffiana and Butia odorata ( $\times$ Butyagrus nabonnandi), it had been previously demonstrated (Elliott et al. 2017) and this study confirmed that $\times B$. nabonnandi is susceptible to $F$. oxysporum f. sp. palmarum. However, Fusarium wilt has not been observed in B. odorata (M. L. Elliott, personal observation). This study indicates that it is susceptible to $F$. oxysporum f. sp. palmarum, at least as a seedling. Perhaps this palm species has simply escaped $F$. oxysporum $\mathrm{f}$. sp. palmarum to date, and dying $B$. odorata should be closely examined for cause of death.

In this study, $W$. filifera was as susceptible to $F$. oxysporum $\mathrm{f}$. sp. palmarum as $W$. robusta, confirming previous results (Giesbrecht et al. 2013). Although Fusarium wilt of $W$. filifera has not been observed in Florida, this is most likely due to this palm's scarcity in the Florida landscape. W. filifera does not thrive or survive in Florida as it does in California and the southwestern United States However, the results of this study are of concern for two reasons. First, W. filifera is a popular palm outside of Florida. Second, the nursery industry has begun promoting an interspecific cross of $W$. robusta and W. filifera (Washingtonia $\times$ filibusta) for use in the Florida landscape. $W$. robusta becomes too tall in most landscapes and is very fast in its growth. By crossing with $W$. filifera, the goal is to obtain a palm with shorter stature and slower growth. However, based on the results reported herein, this cross will probably be just as susceptible to F. oxysporum f. sp. palmarum as W. robusta. There are no other species of Washingtonia (Riffle and Craft 2003).

The Phoenix spp. interactions with $F$. oxysporum f. sp. palmarum confirm that $P$. canariensis is susceptible but also indicate the possibility that $P$. reclinata, $P$. dactylifera, and, to a lesser extent, $P$. sylvestris could be susceptible. Of note, $F$. oxysporum $\mathrm{f}$. sp. palmarum has been isolated from a Fusarium wilt-symptomatic $P$. reclinata $(\mathrm{M}$. L. Elliott, personal observation) but a pathogenicity assay has not yet been completed with that isolate. The most interesting aspect of this study is that
$P$. dactylifera seedlings were significantly affected by $F$. oxysporum $\mathrm{f}$. sp. palmarum, even though this palm species has not been observed to be affected in the landscape, despite the fact $P$. dactylifera is more commonly used in the landscape than $P$. canariensis or $P$. reclinata across the entire state of Florida (M. L. Elliott, personal observation).

In contrast, $F$. oxysporum f. sp. canariensis was only pathogenic to $P$. canariensis and $P$. reclinata, as previously confirmed in Florida (Elliott 2015), and never to $P$. dactylifera. Pathogenicity of $F$. oxysporum $\mathrm{f}$. sp. canariensis to $P$. reclinata has been evaluated outside the United States by Priest and Letham (1996). In their study, when colonized oat grains were incorporated into the potting mix or pruned roots were immersed in a spore suspension prior to planting in containers, $P$. reclinata plants became stunted and most plants had root decay, compared with the control.

Pathogenicity of $F$. oxysporum f. sp. canariensis on $P$. dactylifera has been evaluated numerous times and with different techniques. In France, Mercier and Louvet (1973) used the colonized oat grain technique and determined that their $F$. oxysporum $\mathrm{f}$. sp. canariensis isolate was actually more virulent to $P$. dactylifera than to $P$. canariensis. In California, Feather et al. (1989) conducted both crown injections and root injections of $P$. dactylifera, and both methods resulted in plants with significantly less dry weight than the controls; however, no plants died. Priest and Letham (1996) used this crown injection technique in Australia but they observed no disease development in $P$. dactylifera, even after 18 months. Most recently, Elena (2005) observed disease development in $P$. dactylifera with $F$. oxysporum $\mathrm{f}$. sp. canariensis when roots were immersed in a spore suspension for $24 \mathrm{~h}$. However, despite all of these experimental results, there was no documentation of $F$. oxysporum $\mathrm{f}$. sp. canariensis as a pathogen of $P$. dactylifera on date plantations or landscapes anywhere in the world.

The differing results for $P$. dactylifera in research experiments probably has much to do with the genetics of this palm species. $P$. dactylifera is the only ornamental palm that has cultivars. The numerous cultivars of $P$. dactylifera are maintained by collecting basal offshoots from female plants or, more recently in the Middle East, tissue culture (Chao and Krueger 2007). However, when $P$. dactylifera is grown from seed, as was done in the experiments reported here and by other researchers (Elena 2005; Priest and Letham 1996), no cultivar name can be ascribed to it. Although the $P$. dactylifera plants used in this study were obtained from a nursery in Texas and another in Florida, the source of the seed is unknown.

An alternative explanation for the differing results for $P$. dactylifera could be maturity of the palm. This palm species could be susceptible as an immature palm (not yet fruiting) but not as a mature palm. It is quite possible that this is true for the other palm species evaluated for susceptibility to $F$. oxysporum f. sp. palmarum.

Although the initial screening of $P$. sylvestris indicated that it might be susceptible to $F$. oxysporum $\mathrm{f}$. sp. palmarum, the subsequent experiments were inconclusive. For F. oxysporum f. sp. canariensis, only isolate PLM-387B significantly reduced leaf dry weight of $P$. sylvestris, whether the roots were cut prior to inoculation or not. $P$. sylvestris is a new addition to the Florida landscape but only one palm has ever been documented with Fusarium wilt. Isolate PLM224B was isolated from that palm but pathogenicity has not been demonstrated on $P$. sylvestris, although this isolate did kill or significantly reduce leaf dry weight of $P$. canariensis and $P$. reclinata when the roots were cut prior to inoculation.

Although pathogenicity of $F$. oxysporum f. sp. palmarum has proven to be easy to demonstrate with the assay developed, the pathogen's virulence makes it difficult to evaluate any management methods using this standard pathogenicity assay because either all or most of the inoculated, susceptible palm plants die within 3 months. Based on the results of experiment 8 , root disturbance is not required if a large enough amount of inoculum is applied. This method should be evaluated further using fungicides or other treatments for prevention or mitigation of Fusarium wilt. For example, materials could be incorporated into the potting mix when the palm seedlings are first transplanted, or materials could be applied to palm leaves or soil surface at discrete intervals prior to or after inoculation, or both. 
In summary, two assays have been developed that are relatively easy to conduct and, I advocate, should become the standard for evaluating pathogenicity, and possibly virulence, of the two Fusarium wilt pathogens of ornamental palms: F. oxysporum f. sp. palmarum and $\mathrm{f}$. sp. canariensis. By having a standard pathogenicity assay, comparisons can be made among isolates of these pathogens in other states and countries, without exchange of fungal isolates. These assays also appear to be valid for evaluation of isolate virulence and for determining potential susceptibility of other palm species.

\section{Acknowledgments}

I thank T. Broschat and E. Des Jardin for technical support.

\section{Literature Cited}

Chao, C. T., and Krueger, R. R. 2007. The date palm (Phoenix dactylifera L.): Overview of biology, uses, and cultivation. HortScience 42:1077-1082.

Colhoun, J. 1981. Vascular wilt disease of oil palms. Pages 21-28 in: Fusarium: Diseases, Biology and Taxonomy. P. E. Nelson, T. A. Tousooun, and R. J. Cook, eds. The Pennsylvania State University Press, University Park.

Dunnett, C. W. 1955. A multiple comparisons procedure for comparing several treatments with a control. J. Am. Stat. Assoc. 50:1096-1121.

Elena, K. 2005. Fusarium wilt of Phoenix canariensis: First report in Greece. Plant Pathol. 54:244.

Elliott, M. L. 2011. First report of Fusarium wilt caused by Fusarium oxysporum f. sp. palmarum on Canary Island date palm in Florida. Plant Dis. 95:356.

Elliott, M. L. 2015. First report of Fusarium wilt caused by Fusarium oxysporum f. sp. canariensis on Phoenix reclinata in Florida. Plant Dis. 99:887.

Elliott, M. L., Des Jardin, E. A., Harmon, C. L., and Bec, S. 2017. Confirmation of Fusarium wilt caused by Fusarium oxysporum f. sp. palmarum on $\times$ Butyagrus nabonnandii (mule palm) in Florida. Plant Dis. 101:381.

Elliott, M. L., Des Jardin, E. A., O’Donnell, K., Geiser, D. M., Harrison, N. A., and Broschat, T. K. 2010. Fusarium oxysporum f. sp. palmarum, a novel forma specialis causing a lethal disease of Syagrus romanzoffiana and Washingtonia robusta in Florida. Plant Dis. 94:31-38.

Elliott, M. L., Honeycutt, E., West, J., and Franklin, P. 2011. First report of Fusarium wilt caused by Fusarium oxysporum f. sp. canariensis on Canary Island date palm in Texas and South Carolina. Plant Dis. 95:358.

EPPO. 2003. Fusarium oxysporum f. sp. albedinis. Bull OEPP/EPPO Bull. 33: 265-269.
Feather, T. V. 1982. Occurrence, etiology and control of wilt and dieback of Phoenix canariensis in California. Ph.D. dissertation, University of California, Riverside.

Feather, T. V., Ohr, H. D., Munnecke, D. E., and Carpenter, J. B. 1989. The occurrence of Fusarium oxysporum on Phoenix canariensis, a potential danger to date production in California. Plant Dis. 73:78-80.

Geiser, D. M., Jimenez-Gasco, M. M., Kang, S., Makalowska, I., Veeraraghavan, N., Ward, T. J., Zhang, N., Kuldau, G. A., and O'Donnell, K. 2004 FUSARIUM-ID v. 1.0: A DNA sequence database for identifying Fusarium. Eur. J. Plant Pathol. 110:473-479.

Giesbrecht, M., McCarthy, M., Elliott, M. L., and Ong, K. L. 2013. First report of Fusarium oxysporum f. sp. palmarum in Texas causing Fusarium wilt of Washingtonia robusta. Plant Dis. 97:1511.

Kratz, A., Greenberg, D., Barki, Y., Cohen, E., and Lifshitz, M. 2003. Pantoea agglomerans as a cause of septic arthritis after palm tree thorn injury; case report and literature review. Arch. Dis. Child. 88:542-544.

Louvet, J., and Toutain, G. 1981. Bayoud, Fusarium wilt of date palm. Pages 13-20 in: Fusarium: Diseases, Biology and Taxonomy. P. E. Nelson, T. A. Tousooun, and R. J. Cook, eds. The Pennsylvania State University Press, University Park.

Mercier, S., and Louvet, J. 1973. Recherches sur les fusarioses. X.-Une fusariose vasculaire (Fusarium oxysporum) du palmier des canaries (Phoenix canariensis). Ann. Phytopathol. 5:203-211.

Palmucci, H. E. 2006. Fusarium oxysporum causal agent of wilt on crops of Phoenix canariensis in Argentina. Plant Pathol. 55:304.

Plyler, T. R., Simone, G. W., Fernandez, D., and Kistler, H. C. 1999. Rapid detection of the Fusarium oxysporum lineage containing the Canary Island date palm wilt pathogen. Phytopathology 89:407-413.

Priest, M. J., and Letham, D. B. 1996. Vascular wilt of Phoenix canariensis in New South Wales caused by Fusarium oxysporum. Aust. Plant Pathol. 25:110-113.

Riffle, R. L., and Craft, P. 2003. An Encyclopedia of Cultivated Palms. Timber Press, Inc., Portland, OR.

Singh, R., Castro, A., Ferrin, D. M., Harris, R. S., III, and Olson, B. 2011. First report of Fusarium wilt of Canary Island date palm caused by Fusarium oxysporum f. sp. canariensis in Louisiana. Plant Dis. 95:1192.

Stevens, K. J., Theologis, T., and McNally, E. G. 2000. Imaging of plant-thorn synovitis. Skeletal Radiol. 29:605-608.

Summerell, B. A., Kistler, H. C., and Gunn, L. V. 2001. Fusarium wilt of Phoenix canariensis caused by Fusarium oxysporum f. sp. canariensis. Pages 263-270 in: Fusarium: Paul E. Nelson Memorial Symposium. B. A. Summerell, J. F. Leslie, D. Backhouse, W. L. Bryden, and L. W. Burgess, eds. American Phytopathological Society, St. Paul, MN. 